\title{
MENELUSURI WARISAN BANDUNG: DELEGASI PEREMPUAN DAN SEMANGAT DEKOLONISASI DALAM KONFERENSI WARTAWAN ASIA AFRIKA 1963
}

\author{
TRACKING THE BANDUNG'S LEGACY: WOMEN DELEGATION AND \\ THE SPIRIT OF DECOLONIZATION IN THE 1963 ASIAN AFRICAN \\ JOURNALISTS CONFERENCE
}

\author{
Ayu Wulandari \\ Departemen Sejarah, Universitas Gadjah Mada \\ Jl. Sosiohumaniora, Bulaksumur, Yogyakarta 55281 \\ Email: wulandrayu.99@gmail.com \\ DOI: $10.36424 / j p s b . v 7 i 1.230$
}

Naskah Diterima: 22 Desember 2020 Naskah Direvisi: 14 April 2021

Naskah Disetujui: 15 April 2021

\begin{abstract}
Abstrak
Konferensi Asia Afrika (KAA) 1955 meninggalkan banyak warisan yang terwujud dalam solidaritas Asia Afrika. Salah satu bentuk dari solidaritas tersebut ialah pelaksanaan Konferensi Wartawan Asia Afrika (KWAA) pada 1963 yang menunjukkan solidaritas jurnalis dalam dua kawasan untuk memperkuat semangat dekolonisasi demi melawan kolonialisme dan imperialisme. Penyelenggaraan KWAA meninggalkan banyak kesan yang menarik, salah satunya adalah keterlibatan delegasi perempuan. Sayangnya, kehadiran delegasi perempuan dalam KWAA belum banyak mendapat perhatian dari para akademisi. Oleh karena itu, kajian ini membahas delegasi perempuan dalam KWAA dan suara mereka mengenai semangat dekolonisasi. Kajian ini bertujuan untuk menghadirkan peran perempuan dalam penulisan sejarah diplomasi pascakolonial di Asia Afrika, sehingga penulisan sejarah diplomasi menjadi lebih androgynous. Kajian ini dilakukan dengan metode sejarah, yang hasilnya menunjukkan bahwa beberapa delegasi perempuan yang hadir dalam KWAA adalah "buronan" negaranegara kolonial. Melalui KWAA, mereka menyuarakan pentingnya peran jurnalis dalam mendukung dekolonisasi untuk menghapuskan kolonialisme dan imperialisme di Asia dan Afrika.
\end{abstract}

Kata Kunci: dekolonisasi, delegasi perempuan, jurnalis, Konferensi Wartawan Asia Afrika. 


\begin{abstract}
The Asian-African Conference (AAC) 1955 left a lot of legacy manifested in Asian-African solidarity. One of the legacy was the Asian-African Journalists Conference (AAJC) in 1963, which demonstrated the solidarity of journalists in the two regions to strengthen the spirit of decolonization against colonialism and imperialism. The AAJC left many interesting impressions, especially the involvement of the women delegation. Unfortunately, the presence of women delegates in KWAA has not received much attention from academics. Therefore, this study discusses the women delegation in AAJC and their voices regarding the spirit of decolonization. This study aims to present the role of women in writing the history of post-colonial diplomacy in Asia Africa, so that the writing of diplomatic history becomes more androgynous. This study was conducted using the historical method, the results of which indicated that some of the female delegates who attended the AAJC were "fugitives" from colonial countries. Through AAJC, they voiced the importance of the role of journalists in supporting decolonization to eliminate colonialism and imperialism in Asia and Africa.
\end{abstract}

Keywords: decolonization, women delegation, journalists, the Asian-African Journalists Conference.

\title{
PENDAHULUAN
}

Konferensi Asia Afrika (KAA) merupakan salah satu momentum yang paling penting dalam diplomasi pascakolonial. Konferensi ini diselenggarakan di Bandung pada 18-24 April 1955, dengan dihadiri 29 negara yang belum maupun sudah merdeka dari Asia dan Afrika (Utama, 2017: 88). Pelaksanaan KAA ini berhasil menyita perhatian masyarakat internasional, mengingat saat itu Perang Dingin masih terus berlangsung. Media cetak baik dari negara-negara Blok Barat maupun Blok Timur memberikan perhatian yang besar terhadap penyelenggaraan KAA. Selain itu, KAA juga menghasilkan warisan berupa solidaritas bangsa dan negara-negara Asia Afrika yang terlihat dalam Komunike Bersama dan Dasasila Bandung. Warisan solidaritas KAA juga hadir dalam bentuk konferensi yang menyentuh berbagai kalangan pada tahun-tahun selanjutnya. Salah satu konferensi yang sangat penting adalah Konferensi Wartawan Asia Afrika (KWAA) yang diselenggarakan pada tahun 1963. Konferensi ini tidak lain juga turut 
menunjukkan bahwa kalangan wartawan atau jurnalis menjadi kelompok yang tidak dapat dilepaskan dari pengaruh Konferensi Bandung $1955^{1}$.

Sebagaimana KAA 1955, pelaksanaan KWAA juga menyita perhatian masyarakat internasional. Sayangnya, pelaksanaan KWAA hanya dipandang sebagai momentum naiknya para jurnalis Asia Afrika - tentunya, para jurnalis laki-laki. Sejauh ini, tidak banyak akademisi ataupun masyarakat yang memperhatikan keterlibatan jurnalis perempuan yang menjadi bagian dari delegasi negara peserta konferensi. Padahal, dalam KWAA juga terdapat beberapa delegasi perempuan. Hal ini setidaknya menunjukkan bahwa para delegasi perempuan tersebut memiliki peranan yang penting dalam mewujudkan semangat Bandung 1955 melalui KWAA, terutama untuk mengobarkan semangat dekolonisasi. Mengenai dekolonisasi, upaya ini pada dasarnya telah berlangsung sejak berakhirnya Perang Dunia II, dimana negara bekas jajahan berupaya melakukan delegitimasi terhadap kekuasaan politik maupun segala hubungan perhambaan dengan elite asing atau penjajah (Jansen, 2017: 1-2). Seiring dengan perkembangannya, upaya dekolonisasi tidak hanya dilakukan oleh para elite politik, melainkan juga aktor di luar politik dan pemerintahan (non state) seperti kaum perempuan. Bahkan, kaum perempuan memiliki organisasi bagi perjuangan untuk menghancurkan kolonialisme dan imperialisme seperti WIDF (Women's International Democratic Federation). Dalam organisasi tersebut, perempuan dari berbagai profesi menyatukan semangat mereka untuk mempercepat sekaligus memperkuat upaya dekolonisasi, termasuk di wilayah Asia dan Afrika.

Keterlibatan perempuan dalam upaya dekolonisasi di Asia dan Afrika juga ditunjukkan oleh para jurnalis perempuan yang kemudian terlihat dalam KWAA. Namun sebagaimana telah disebutkan sebelumnya, sejauh ini keterlibatan delegasi perempuan dalam KWAA belum mendapat banyak perhatian. Karenanya, dapat dikatakan bahwa hingga saat ini kaum perempuan masih mengalami pemarginalan dalam kajian mengenai KWAA. Ketiadaan dan atau pemarginalan delegasi perempuan dalam KWAA setidaknya diakibatkan oleh penulisan sejarah

\footnotetext{
${ }^{1}$ Terminologi “Konferensi Bandung” merujuk ke Konferensi Asia Afrika tahun 1955.
} 
diplomasi secara umum atau sejarah KAA dan warisan-warisannya yang hanya memperhatikan peranan kaum laki-laki. Bahkan, dapat dikatakan bahwa glorifikasi terhadap peranan laki-laki menjadi sangat kuat dalam penulisan sejarah diplomasi. Namun, pemarginalan perempuan dalam konteks ini juga barangkali disebabkan oleh fakta bahwa tidak semua akademisi ataupun sejarawan memiliki sensitivitas pada isu gender. Penyebab lain misalnya, perlu disadari bahwa momen diplomatik baik di level bilateral, regional, maupun internasional memang didominasi oleh delegasi laki-laki, sementara kaum perempuan kurang terakomodasi. Karenanya, sejauh ini belum muncul pertanyaan bahwa apakah KWAA ataupun pertemuan diplomatik lainnya melibatkan delegasi perempuan.

Kemudian untuk memetakan sejauh mana pemarginalan terhadap peranan perempuan telah terjadi, maka menjadi penting untuk memperhatikan kajiankajian yang telah ada. Dalam Sejarah Diplomasi Republik Indonesia dari Masa ke Masa yang diterbitkan oleh Departemen Luar Negeri (1996), dapat disimpulkan bahwa mayoritas upaya diplomasi Indonesia dilakukan oleh kaum laki-laki. Dalam kajian tersebut, peran kaum perempuan bahkan tidak mendapatkan porsi pembahasan. Selain itu, kajian tersebut juga hanya memperhatikan momenmomen diplomasi yang secara resmi melibatkan diplomat dari kalangan pemerintahan. Sementara itu, momen-momen diplomasi yang melibatkan aktor non-state atau dari luar pemerintahan seperti penulis, jurnalis, ataupun yang lainnya, tidak disinggung dalam kajian tersebut. Karenanya, penyelenggaraan KWAA juga tidak menjadi bagian yang penting dalam Sejarah Diplomasi Republik Indonesia dari Masa ke Masa.

Dalam kajian lain yang membahas mengenai diplomasi ataupun politik luar negeri, peran perempuan belum mendapat tempat. Leifer (1989) Politik Luar Negeri Indonesia, sebenarnya telah secara detail mengulas kebijakan politik luar negeri dan pelaksanaannya di Indonesia dari masa ke masa. Akan tetapi, Leifer sama sekali tidak menyinggung peranan kaum perempuan. Karenanya, kajian Leifer semakin mempertebal kesan bahwa kebijakan politik luar negeri dan pelaksanaannya yang termanifestasi dalam misi diplomasi hanya merupakan lahan 
yang dikuasai oleh kaum laki-laki. Kemudian, Agung (1990) dalam kajiannya yang berjudul Twenty Years Indonesian Foreign Policy 1945-1965 juga tidak memperhatikan peran perempuan dalam pelaksanaan politik luar negeri Indonesia. Dengan demikian, penulisan mengenai sejarah diplomasi memang belum sepenuhnya mendapatkan tempat dalam historiografi Indonesia.

Sementara itu, mengenai KWAA yang menjadi fokus utama dari kajian ini, sejauh ini juga belum mendapatkan perhatian dari para akademisi. Bahkan, dapat dikatakan bahwa penulisan sejarah mengenai KWAA masih sangat terbatas. Karenanya, peranan kaum perempuan sebagai anggota delegasi dalam KWAA juga sejauh ini belum dihadirkan. Zhou (2019) dalam kajiannya yang berjudul Global Reporting from The Third World: The Afro-Asian Journalists' Association, 1963-1974 sebenarnya telah menyinggung mengenai KWAA. Hanya saja, Zhou menempatkan KWAA sebagai akar dari Afro-Asian Journalists' Association (AAJA) yang menjadi warisan dari KWAA. Sayangnya ketika menyinggung pelaksanaan KWAA, Zhou tidak memperhatikan mengenai peranan delegasi perempuan - terutama dalam konteks menyuarakan spirit dekolonisasi seperti antikolonialisme, anti imperialisme, dan antineokolonialisme.

Dalam historiografi Indonesia ataupun Asia Afrika secara keseluruhan, peran perempuan lebih ditampilkan dalam penulisan sejarah pergerakan perempuan. Vreede-de Stuers (2008) dalam Sejarah Perempuan Indonesia, Gerakan dan Pencapaian, menyatakan bahwa kaum perempuan memiliki peranan penting dalam sejarah bangsa Indonesia. Kemudian, Jati (2014) dalam Gerakan Perempuan di Indonesia dari Masa ke Masa lebih lanjut menganalisis mengenai peran perempuan dalam organisasi pergerakan. Pada masa sebelum kemerdekaan, perempuan banyak bergerak dalam bidang sosial melalui berbagai organisasi seperti Wanita Oetomo, Aisyiah, dan organisasi lainnya (Jati, 2014: 285). Kemudian pasca kemerdekaan, perempuan terlibat dalam gerakan yang lebih besar seperti Gerwani dan mulai tampil dalam panggung politik. Pada dasarnya, keterlibatan perempuan dalam ruang publik tersebut juga dipengaruhi oleh gagasan antikolonialisme yang meluas di Indonesia. 
Sementara itu, kehadiran perempuan sebagai delegasi atau dengan kata lain sebagai aktor dalam momen-momen diplomasi di Indonesia maupun Asia Afrika secara keseluruhan sejauh ini berada di luar pembahasan mengenai KWAA. Wulandari (2020) dalam Kaum Perempuan dalam Diplomasi Kebudayaan Indonesia 1945-1960an telah menguraikan peranan kaum perempuan dalam misi diplomasi kebudayaan Indonesia sejak kemerdekaan hingga berakhirnya masa pemerintahan Presiden Soekarno. Kajian tersebut menunjukkan bahwa kaum perempuan sepanjang periode tersebut telah mendekonstruksi posisinya sebagai konco wingking - sebuah konsep yang telah mendarah daging dalam kultur masyarakat Indonesia - menjadi aktor yang bermain penting dalam diplomasi sebagai sebuah sektor publik.

Kemudian, Armstrong (2016) dalam kajiannya yang berjudul Before Bandung: The Anti-Imperialist Women's Movement in Asia and the Women 's International Democratic Federation sebenarnya dengan sangat detail telah menghadirkan peranan perempuan sebagai delegasi dalam momen-momen diplomasi. Dalam kajian tersebut, Armstrong menegaskan perhatiannya pada konferensi khusus perempuan Asia yang diselenggarakan sebelum KAA 1955. Karenanya, KWAA tidak menjadi bagian dari kajian Armstrong. Namun, kajian Armstrong setidaknya telah menunjukkan bahwa eksistensi kaum perempuan di Asia bukan hanya pada pertemuan atau konferensi regional, tetapi secara perlahan juga mewujud dalam bentuk solidaritas lainnya, yang mana hal ini sangat terlihat pasca Bandung 1955. Gagasan yang hampir sama juga ditawarkan oleh Lewis (2019) melalui karyanya yang berjudul Asian Socialists and the Forgotten Architects of Post-Colonial Freedom. Dalam kajiannya, Lewis (2019) menempatkan perempuan sebagai salah satu bagian yang penting dalam pelaksanaan Asian Socialist Conference. Meskipun tidak mengkaji KWAA, namun kajian Lewis mampu memberikan gambaran mengenai solidaritas delegasi perempuan dalam pertemuan regional maupun internasional pada dekade 1950an.

Dari tinjauan beberapa kajian yang ada, dapat disimpulkan bahwa sejauh ini penulisan mengenai KWAA masih sangat terbatas. Terlebih mengenai delegasi 
perempuan dan perannya dalam menyuarakan antikolonialisme melalui KWAA, bahkan belum mendapatkan tempat dalam penulisan sejarah diplomasi. Oleh karena itu, kajian ini hadir untuk menjelaskan peran delegasi perempuan dalam KWAA, terutama dalam konteks menyuarakan dan memperkuat semangat dekolonisasi. Secara historiografis, besar harapan bahwa kajian ini dapat mengisi kekosongan penulisan sejarah diplomasi yang sejauh ini masih memusatkan perhatiannya pada peranan kaum laki-laki. Karenanya, diharapkan bahwa kajian ini dapat mendorong penulisan sejarah diplomasi yang lebih androgynous, dimana ada porsi yang "seimbang” antara peran perempuan dan laki-laki.

\section{METODE PENELITIAN}

Kajian ini disusun menggunakan metode penelitian sejarah, yang terdiri dari pemilihan topik, pengumpulan sumber atau heuristik, verifikasi, interpretasi, dan diakhiri dengan penulisan atau historiografi (Kuntowijoyo, 2013:69). Proses heurtistik atau pengumpulan sumber dilakukan dengan mengunjungi beberapa institusi seperti Perpustakaan Nasional RI, Perpustakaan Pusat UGM, dan beberapa institusi lainnya. Kajian ini disusun dengan sumber primer berupa artikel dan berita dari berbagai majalah dan surat kabar, sementara buku-buku referensi, artikel jurnal, dan sumber lainnya diklasifikasikan sebagai sumber sekunder. Setelah mengumpulkan sumber, proses selanjutnya adalah melakukan verifikasi atau kritik sumber. Verifikasi dilakukan dengan membandingkan isi satu sumber dengan sumber lainnya, baik primer maupun sekunder, untuk memperoleh fakta sejarah yang dapat dipercaya. Tahap ketiga dari penelitian ini adalah interpretasi, yaitu menafsirkan fakta sejarah yang telah didapatkan melalui proses sebelumnya. Adapun proses terakhir dari penelitian ini adalah historiografi, yaitu menuliskan fakta sejarah yang telah diinterpretasi menjadi rekonstruksi sejarah yang kronologis, objektif, dan analitis. 


\section{PEMBAHASAN}

\section{KWAA sebagai Warisan Bandung 1955}

Sebagaimana telah disebutkan dalam bagian awal kajian ini, pelaksanaan KAA di Bandung pada tahun 1955 telah meninggalkan warisan berupa solidaritas Asia Afrika. Meskipun KAA lebih berupa pertemuan aktor-aktor diplomasi yang merupakan bagian dari pemerintahan, namun solidaritas Asia Afrika yang tumbuh pasca Bandung 1955 mampu menembus batas-batas institusi. Jurnalis sebagai aktor non-state pun tidak terlepas dari euforia solidaritas tersebut. Bahkan, solidaritas jurnalis Asia Afrika bukan sekadar kekuatan orang-orang yang berkumpul dengan profesi yang sama, melainkan juga menjadi bagian dari komitmen bangsa dan negara di Asia Afrika untuk menghancurkan kolonialisme, imperialisme, dan neokolonialisme melalui pers. Dengan demikian, para jurnalis juga turut menjadi corong bagi semangat dekolonisasi.

Konferensi Wartawan Asia Afrika diselenggarakan pada tahun 1963, setelah berbagai konferensi massal yang mengusung solidaritas Asia Afrika dilaksanakan. Sebelum konferensi inti dilaksanakan, Panitia KWAA terlebih dahulu mengadakan konferensi pendahuluan yang diselenggarakan pada 11 sampai 15 Februari 1963 di "Bali Room" Hotel Indonesia, Jakarta ("K.W.A.A. Penting bagi Perdjuangan...", Mei 1963: 42). Pada dasarnya, konferensi pendahuluan tersebut membahas tentang teknis pelaksanaan KWAA. Namun, konferensi pendahuluan juga diadakan guna menguatkan pedoman KWAA. Berdasarkan berita yang dimuat dalam Mimbar Penerangan ("K.W.A.A. Penting bagi Perdjuangan...", Mei 1963: 43), maka ditekankan bahwa pedoman KWAA adalah Dasasila Bandung. Dasasila Bandung dinilai dapat mendorong para jurnalis yang terlibat dalam KWAA untuk membantu perjuangan memperoleh dan mempertahankan kemerdekaan bagi negara-negara Asia Afrika. Selain itu, ditegaskan pula bahwa pelaksanaan KWAA tidak lain juga berkaitan dengan upaya memperluas dan memperkuat jaringan antikolonialisme.

Namun, keputusan untuk menjadikan KWAA sebagai bagian dari perjuangan melawan kolonialisme tidak disetujui oleh seluruh negara peserta 
konferensi. Ada anggapan bahwa pers dan jurnalis tidak dapat dikaitkan dengan urusan politik, sehingga KWAA tidak layak untuk mengadopsi Dasasila Bandung sebagai dasarnya. Namun, Djawoto sebagai Ketua Panitia Penyelenggara KWAA dengan tegas menyatakan bahwa,

“...memang benar bahwa organisasi-organisasi wartawan adalah organisasi-organisasi bukan pemerintah, tetapi kami jakin bahwa tak ada wartawan terutama wartawan A.A. (Asia Afrika) jang dapat menjatakan bahwa profesi djurnalistik dapat dilepaskan dari soal politik. Tiap hari surat kabar selalu penuh dengan soal-soal politik, bahkan mempunyai fungsi sebagai pemupuk pendapat umum dalam soal itu” (“K.W.A.A. Penting bagi Perdjuangan...", Mei 1963: 44).

Pernyataan yang mendukung KWAA sebagai penerus semangat Bandung 1955 dan sebagai lahan untuk memperkuat antikolonialisme juga diucapkan oleh Roeslan Abdulgani dalam konferensi pendahuluan tersebut. Dalam pidato sambutannya, Roeslan Abdulgani menyatakan bahwa “...mendjadi tanggung djawab pers pula untuk menebarkan dan mengembangkan semangat Bandung tidak hanja ke pada generasi kita tetapi djuga kepada dunia agar kebenaran semangat itu dapat dijakini oleh setiap orang" (“K.W.A.A. Penting bagi Perdjuangan...”, Mei 1963: 45). Karenanya, KWAA tetap dilaksanakan dengan mengakar pada Dasasila Bandung, terutama dalam rangka memperkuat semangat antikolonialisme.

Pascakonferensi pendahuluan, KWAA kemudian diselenggarakan pada April 1963. Berbeda dengan KAA 1955 yang diselenggarakan di Bandung, Panitia Penyelenggara KWAA memilih Jakarta sebagai lokasi pelaksanaan konferensi. KWAA dimulai pada tanggal 24 April 1963, bertepatan dengan Hari Kesetiakawanan Asia Afrika. Dalam konferensi tersebut, Presiden Soekarno secara langsung memberikan sambutannya dalam acara pembukaan ("Mengenang Kembali Peristiwa Penting..." , Desember 1963: 76). Selain dihadiri oleh Presiden Soekarno, hadir pula tokoh-tokoh nasional seperti PM Djuanda, Menteri Luar Negeri Soebandrio, Nyonya Hartini Soekarno, dan tokoh-tokoh nasional lainnya dari lembaga pemerintah (“K.W.A.A. Penting bagi Perdjuangan...”, Juni 
1963: 53). Konferensi tersebut dihadiri oleh sekitar 130 jurnalis dari lebih tiga puluh negara. Adapun negara yang mengirimkan delegasinya antara lain Indonesia, Burma (Myanmar), Malaya, Rhodesia Selatan, Vietnam Selatan, Sudan, Turki, Kamboja, Jepang, India, Srilanka, hingga Republik Rakyat Tiongkok (RRT).

Sebagaimana yang telah disepakati dalam konferensi pendahuluan, KWAA dilaksanakan sepenuhnya untuk mendukung perjuangan politik negaranegara Asia dan Afrika. Presiden Soekarno dalam pidato sambutannya menyatakan bahwa pers Asia Afrika merupakan alat perjuangan, yang seharusnya dapat mendorong transformasi bangsa-bangsa di Asia dan Afrika untuk mencapai kemerdekaan, keadilan, dan turut berpartisipasi dalam mengubah wajah dunia (“K.W.A.A. Penting bagi Perdjuangan...”, Juni 1963: 53). Apalagi, KWAA diselenggarakan ketika kontestasi politik antara Blok Barat dengan Blok Timur masih berlangsung. Karenanya, menyuarakan semangat kemerdekaan, keadilan, perdamaian, dan antikolonialisme dianggap penting dalam agenda KWAA.

Pernyataan Presiden Soekarno mengenai keterkaitan antara KWAA dengan perjuangan Asia Afrika juga didukung oleh delegasi lainnya. M. Cologo, Menteri Muda Penerangan Mali, yang mewakili delegasi jurnalis Afrika dalam pidatonya menyatakan dengan tegas bahwa tujuan KWAA adalah untuk mengalahkan imperialisme yang selalu menghalangi kemajuan bangsa-bangsa di Asia dan Afrika (“K.W.A.A. Penting bagi Perdjuangan...”, Juni 1963: 55). Sementara itu, Y. Kobayashi yang merupakan jurnalis dari Jepang juga turut memberikan pernyataannya mengenai KWAA. Mewakili jurnalis dari Asia, Kobayashi menegaskan bahwa KWAA harus mampu mendorong para jurnalis dan pers Asia Afrika untuk memperkuat solidaritas Asia Afrika dalam rangka mencegah kekuatan reaksioner yang menghalangi kemajuan (“K.W.A.A. Penting bagi Perdjuangan...", Juni 1963).

Pelaksanaan KWAA berlangsung hingga 30 April 1963. Dalam penutupan konferensi, dihasilkan beberapa keputusan yang menjadi sangat penting bagi solidaritas Asia Afrika. Pertama, ialah Djakarta Declaration yang sebenarnya 
telah disusun sejak konferensi pendahuluan pada Februari 1963 (“K.W.A.A. Penting bagi Perdjuangan...", Juni 1963: 57). Secara umum, Djakarta Declaration berisi komitmen jurnalis Asia Afrika untuk mengabdikan diri pada perjuangan bangsa-bangsa Asia Afrika. Keputusan lainnya yang tidak kalah penting ialah resolusi yang dihasilkan dari KWAA. Komite I konferensi yang bertugas mengurusi masalah politik secara resmi mengusulkan KWAA sebagai bagian dari perjuangan melawan kolonialisme dan imperialisme.

Usulan tersebut diterima oleh Komite II yang merupakan Komite Organisasi, sehingga kemudian disahkan menjadi resolusi. Resolusi tersebut mendukung para jurnalis, pers, dan bangsa-bangsa di Asia Afrika untuk melawan kolonialisme dalam bentuk lama maupun baru. Agaknya perlu disadari bahwa Perang Dingin yang meluas hingga ke Asia dan Afrika juga telah menciptakan ruang-ruang kolonialisme yang baru, dimana hal tersebut mengganggu stabilitas kawasan.

KWAA kemudian berakhir pada tanggal 30 April 1963. Meskipun konferensi inti berlangsung di Jakarta, namun resepsi penutupan KWAA dilaksanakan di Bandung, tepatnya di Gedung Asia Afrika ("K.W.A.A. Penting bagi Perdjuangan...", Juni 1963: 60). Sementara itu, pemilihan tanggal 30 April 1963 sebagai hari terakhir konferensi, pada dasarnya memiliki alasan yang sangat politis. Perlu diketahui bahwa penutupan konferensi dilakukan pada malam hari, sehingga dapat dikatakan bahwa saat itu telah menjelang tanggal 1 Mei 1963. Panitia Penyelenggara KWAA memilih waktu tersebut untuk merayakan penyerahan Irian Barat secara resmi dari UNTEA kepada Pemerintah Indonesia (“K.W.A.A. Penting bagi Perdjuangan...”, Juni 1963: 60). Tentu, hal itu secara tidak langsung semakin memperkuat pandangan bahwa KWAA menjadi simbol perlawanan terhadap kolonialisme dan imperialisme - sebagaimana perjuangan pembebasan Irian Barat yang oleh Pemerintah Indonesia selalu digaungkan sebagai perjuangan melawan kolonialisme Belanda. Kemudian pada keesokan harinya, para peserta konferensi mendapatkan jamuan resepsi penutupan di Hotel Homann, dimana malam harinya juga diadakan pertunjukan kesenian. 
Jika diperhatikan lebih lanjut, tentu muncul pertanyaan mengapa KWAA memilih Bandung sebagai lokasi penutupan konferensi? Pertanyaan tersebut mau tidak mau mengantarkan kita pada gagasan yang telah ditawarkan sebelumnya, bahwa KWAA merupakan bagian dari warisan KAA 1955. Hal ini dapat dilihat pada pidato Roeslan Abdulgani pada penutupan konferensi, dimana Roeslan dengan tegas menyatakan,

“...Pada tahun 1955 kita menjebut bahwa Bandung adalah ibukota Asia-Afrika, bahwa Bandung adalah Asia-Afrika bentuk ketjil, tetapi Bandung menjadari sepenuhnya tanpa rakjat-rakjat AsiaAfrika, Bandung tidak akan mempunjai arti apa-apa. Delapan tahun jang lalu gedung ini penuh sesak dengan negarawannegarawan pemimpin-pemimpin dan delegasi-delegasi dari 29 negara-negara Asia-Afrika jang membela semangat perdamaian dan ko-eksistensi serta menjatakan bahwa perdamaian dan kemerdekaan tak dapat dipisah-pisahkan. Delapan tahun jang lalu gedung ini merupakan suatu ruangan jang padat dengan kebulatan semangat yang menggugat kolonialisme dan imperialisme" (“K.W.A.A. Penting bagi Perdjuangan...", Juni 1963: 60-61).

Dengan demikian, dapat dikatakan bahwa ada upaya untuk mengingatkan delegasi KWAA terhadap akar dari pelaksanaan konferensi, yaitu Bandung 1955 dengan komitmennya untuk mendukung dekolonisasi demi menghancurkan segala bentuk kolonialisme dan imperialisme.

\section{Delegasi Perempuan dalam KWAA dan Semangat Dekolonisasi}

Pelaksanaan KWAA pada dasarnya tidak dapat dilepaskan dari peranan kaum perempuan. Agaknya, kehadiran delegasi perempuan dalam KWAA juga turut dipengaruhi oleh gerakan feminisme yang meluas di wilayah Asia dan Afrika, sehingga perempuan mampu terjun ke dalam ranah publik. Padahal secara kultural, perempuan dalam konstruksi masyarakat luas selalu dianggap sebagai the others dari kaum laki-laki (Minarova-Banjac, 2018: 23). Dengan kata lain, kaum perempuan menjadi kaum yang dikecualikan dalam ranah publik dan urusanurusan yang menyangkut politik ataupun pemerintahan. Machiavelli sebagaimana dikutip oleh Tickner (1992: 39), menggambarkan perempuan sebagai ancaman 
yang harus dijauhi dan dihancurkan oleh laki-laki. Tentu, pemikiran semacam itu menimbulkan penafsiran yang melekatkan kaum perempuan dengan kerusakan, kekacauan, ataupun kehancuran dalam ranah publik. Karenanya, kaum perempuan menjadi termarginalkan dalam urusan-urusan strategis, terutama politik luar negeri dan diplomasi.

Namun seiring meluasnya gagasan feminisme, kaum perempuan semakin mendapatkan tempat dalam urusan diplomasi. Meskipun pada kenyataannya, masuknya perempuan ke dalam momen-momen diplomasi seperti di Eropa sebenarnya bukanlah fenomena yang baru (Aggestam dan Towns, 2018: 13). Akan tetapi di Asia dan Afrika, kehadiran perempuan dalam diplomasi baru terlihat jelas setidaknya pada tahun 1950an, dan terlihat sebagai fenomena yang "umum" pada tahun 1960an. Meskipun sebenarnya, kehadiran perempuan ke dalam ruang-ruang diplomasi di Asia dan Afrika bukanlah respons dari anggapan bahwa kaum perempuan di selatan tertinggal dari kemajuan kaum perempuan di utara. Pada dasarnya, langkah perempuan ke dalam ruang diplomasi pascakolonial di Asia dan Afrika dituntut oleh kebutuhan negara saat itu untuk menghancurkan kolonialisme. Berkaca pada dinamika yang terjadi sebelum 1955, kaum perempuan di Indonesia, India, dan negara-negara lainnya di Asia dan Afrika telah menjadi bagian dari gerakan perlawanan terhadap kolonialisme. Lebih dari itu, kaum perempuan Asia dan Afrika pada dasarnya juga telah hadir ke dalam panggung diplomasi global melalui PBB. Bahkan, Vijaya Laksmi Pandhit dari India pernah menduduki peran sebagai Presiden Sidang Umum PBB (Stone, Desember 1955: 17).

Kembali pada pelaksanaan KWAA, kaum perempuan menyambut baik adanya konferensi ini. Terutama kaum perempuan Indonesia yang menjadi tuan rumah konferensi, menilai bahwa KWAA menjadi menarik dengan datangnya srikandi pers Asia Afrika. Berlatar semangat dekolonisasi yang diwariskan KAA 1955, muncul harapan bahwa jurnalis perempuan juga turut berperan dalam upaya dekolonisasi ini. Dengan demikian, dapat dipastikan bahwa delegasi perempuan juga turut hadir dalam konferensi massal ini. Sejauh ini, memang belum 
ditemukan catatan resmi mengenai berapa jumlah tokoh perempuan yang mendapatkan tugas sebagai delegasi. Namun berdasarkan cerita dari Lies Said (1963), tidak kurang dari sepuluh jurnalis perempuan yang masuk ke dalam jajaran delegasi. Jumlah ini memang lebih sedikit jika dibandingkan dengan jumlah jurnalis laki-laki, namun hal ini tidak menyurutkan semangat para jurnalis perempuan tersebut untuk turut menyuarakan dekolonisasi dan memperkuat semangat antikolonialisme serta antiimperialisme. Terlebih lagi, para jurnalis perempuan tersebut memiliki pengalamannya sendiri mengenai kekejaman kolonialisme dan imperialisme. Hal ini mengacu pada pernyataan Said (1963: 3) yang menegaskan bahwa hampir semua delegasi perempuan yang hadir dalam KWAA adalah buronan kaum kolonialis dan imperialis. Kedatangan para delegasi perempuan tersebut ke KWAA pun pada dasarnya tidak dapat dilepaskan dari semangat mereka untuk menggugat kolonialisme dan imperialisme (Said, 1963: $3)$.

Lalu, siapa sajakah delegasi perempuan yang hadir dalam KWAA dan bagaimana mereka turut menyuarakan dekolonisasi melalui konferensi tersebut? Sebelum melangkah lebih jauh, agaknya perlu dipahami bahwa delegasi perempuan dalam KWAA tidak menduduki posisi yang strategis. Artinya, tidak banyak dari mereka yang dapat memberikan pidato sambutannya ataupun pernyataannya di depan seluruh peserta konferensi secara resmi. Akan tetapi, hal ini bukan berarti bahwa para delegasi perempuan tidak turut menyuarakan gagasan mereka tentang antikolonialisme dan antiimperialisme. Karena tidak mendapat tempat dalam "diplomasi” formal selama konferensi, para delegasi perempuan justru melakukan "diplomasi” informal, yakni dengan melakukan percakapan ringan dengan sesama delegasi konferensi. Melalui percakapan tersebut, mereka menceritakan kondisi penjajahan di negaranya masing-masing, sehingga para delegasi perempuan tersebut turut berperan mempertebal semangat antikolonialisme dan antiimperialisme melalui KWAA.

Yang pertama, menjadi penting untuk mengetahui kaum perempuan yang menjadi bagian dari delegasi Indonesia. Dari Indonesia, terdapat tiga tokoh 
perempuan yang menjadi anggota delegasi yakni Lies Said, Supeni Pudjobuntoro, dan Ani Idrus (Said, 1963: 5). Lies Said merupakan perwakilan dari PWI Jakarta, sekaligus juga mewakili Majalah Wanita (“Wanita Menjambut K.W.A.A.”, Maret 1963: 1). Sepanjang konferensi berlangsung, Lies Said kerap berbincang dengan delegasi perempuan dari negara lainnya. Perbincangannya dengan mereka tidak jauh-jauh dari topik kolonialisme dan imperialisme. Pada dasarnya, hal ini secara tidak langsung turut memperkuat perasaan dan gerakan antikolonialisme dan antiimperialisme diantara para delegasi perempuan dalam KWAA.

Kemudian, terdapat Supeni Pudjobuntoro yang juga duduk dalam delegasi Indonesia. Selama konferensi berlangsung, Supeni menduduki jabatan sebagai Ketua Komite II yang mengurus masalah organisasi khusus jurnalis Asia Afrika (“Sukses dalam K.W.A.A”, Februari 1963: 1). Sebagaimana Lies Said, Supeni juga turut menyuarakan kepada para delegasi KWAA untuk menentang kolonialisme dan imperialisme. Sebenarnya, bukan sesuatu yang baru jika Supeni begitu keras menentang segala bentuk penjajahan, mengingat latar belakangnya yang memang menjadi salah satu pejuang kemerdekaan melalui organisasi perempuan. Selain Supeni, Ani Idrus juga hadir sebagai delegasi yang turut menentang kolonialisme dan imperialisme. Sayangnya, hingga saat ini tidak banyak catatan mengenai bagaimana Ani Idrus turut menyuarakan kemarahannya pada penjajahan tersebut. Namun, perlu ditekankan pula bahwa giatnya delegasi perempuan Indonesia dalam KWAA juga dipengaruhi oleh Presiden Soekarno yang mendominasi arah pelaksanaan politik luar negeri Indonesia. Apalagi, KWAA ini dilaksanakan pada era "Demokrasi Terpimpin", dimana kepribadian Soekarno turut mendominasi politik dan bahkan beberapa pengamat menilainya sebagai seorang diktator (Ricklefs, 2008: 533). Pada era ini, diplomasi yang dilakukan oleh Pemerintah Indonesia untuk melawan kolonialisme dan imperialisme memang menjadi sangat ofensif, yang bahkan kemudian dinamakan sebagai "diplomasi revolusioner" (Wuryandari, peny. 2008: 94-95).

Kemudian, jurnalis perempuan yang paling menyita perhatian Indonesia adalah Djamila Bouhired. Ia merupakan delegasi dari Aljazair yang namanya 
sudah tak asing lagi bagi masyarakat Indonesia ("Wanita Menjambut K.W.A.A.", Maret 1963: 1). Djamila Bouhired bersama suaminya menerbitkan perjuangan revolusi rakyat Afrika melalui majalah yang mereka dirikan. Tidak heran, Djamila Bouhired dengan profesinya sebagai jurnalis pun menjadi salah satu simbol dekolonisasi di Aljazair. Nyonya Mudigdo (1958) salah satu tokoh Gerwani pernah menyinggung Djamila Bouhired dalam tulisannya sebagaimana dikutip oleh McGregor (dalam Mooney dan Lanza, peny., 2013: 39) bahwa

"The majority of men and women in the world, including those of Asia and Africa, desire peaceful coexistence, as laid down in the principles of the Bandung conference. But the instigators of war are still indulging in aggressive acts, as they did in Egypt during the Suez Canal conflict, and in Algeria, where the people are fighting for their liberation and where the heroine, Djamila Bouhired, has become the symbol of their fight."

"Mayoritas laki-laki dan perempuan di dunia, termasuk di Asia dan Afrika, menginginkan hidup berdampingan secara damai, seperti yang ditetapkan dalam prinsip-prinsip konferensi Bandung. Tetapi para pemicu perang masih melakukan tindakan agresif, seperti yang mereka lakukan di Mesir selama konflik Terusan Suez, dan di Aljazair, dimana orang-orang berjuang untuk pembebasan mereka dan dimana pahlawan perempuan, Djamila Bouhired, telah menjadi simbol perjuangan mereka."

Selanjutnya, terdapat delegasi perempuan yang memiliki posisi penting dalam KWAA. Bahkan, ia menjadi satu-satunya delegasi perempuan yang menduduki presidium KWAA. Ialah Nancy Grant, seorang jurnalis yang mewakili Sierre Leone. Selama pelaksanaan KWAA, Nancy Grant rutin bercerita mengenai kondisi penjajahan di negaranya. Melalui penuturan Said (1963: 4), diketahui bahwa Nancy Grant menjadi tokoh perempuan yang cukup sering mengobarkan pidato di negaranya untuk memperkuat gerakan antikolonialisme dan antiimperialisme. Apalagi, penjajahan yang terjadi di negaranya telah menyentuh pada tataran diskriminasi ras, sehingga suara Nancy Grant mengenai antikolonialisme dan antiimperialisme sangat penting untuk mendobrak penjajahan tersebut. Pada dasarnya, pandangan Nancy Grant yang sangat menentang kolonialisme dan imperialisme sangat mempengaruhi para peserta 
delegasi di KWAA agar tetap mendukung KWAA mengakar pada Dasasila Bandung. Sebagaimana disebutkan sebelumnya, tidak semua delegasi menyetujui KWAA menggunakan Dasasila Bandung sebagai pedomannya. Karenanya, ceritacerita Nancy Grant tentang diskriminasi dan penjajahan yang terjadi di negaranya - apalagi ia turut menduduki presidium konferensi - sebenarnya turut menjadi bagian dari negosiasi agar seluruh delegasi dalam KWAA menyetujui untuk menggunakan Dasasila Bandung sebagai pedomannya.

Selain Sierre Leone, Portugis Guinea juga mengirimkan delegasi perempuan, yakni Lucette Andrade. Lies Said sempat berbincang dengan Lucette ketika KWAA berlangsung. Lucette Andrade merupakan salah satu jurnalis dari bulletin Libertacao, sebuah bulletin yang menyuarakan perlawanan terhadap kolonialisme dan imperialisme. Hal ini dikarenakan saat itu mereka tengah dijajah oleh Portugis. Lucette menceritakan bahwa meskipun bekerja sebagai jurnalis, namun ia tidak dapat menyebarkan bulletin yang dikelolanya dalam jumlah banyak. Bahkan, penyiaran bulletin itu seringkali dilakukan secara diam-diam, atau bahkan untuk mendistribusikan bulletin tersebut ke wilayah pedalaman harus melalui penyelundupan terlebih dahulu (Said, 1963: 4). Tidak jarang pula Lucette Andrade dan rekan kerjanya harus bekerja di bawah tanah (underground). Namun, untuk berbicara lebih jauh tentang kolonialisme dan imperialisme di negaranya, Lucette harus dibantu oleh Cabral Vasco yang menjadi ketua delegasi. Hal ini dikarenakan Lucette tidak begitu mahir berbahasa Inggris. Melalui penuturan Cabral Vasco, diketahui bahwa Lucette bersama pejuang antikolonial dan antiimperial di Portugis Guinea menjadi buronan Pemerintah Kolonial Portugis. Lebih lanjut Cabral Vasco mengatakan, bahwa ia dan Lucette Andrade bahkan saat itu dilarang untuk pulang ke Portugis-Guinea, sehingga sepulang dari KWAA mereka pulang ke markas perjuangannya di Conakry (Said, 1963: 4).

Sebagaimana Lucette Andrade yang harus melawan kolonialisme dan imperialisme melalui bawah tanah, Nguyen Thi Binh yang merupakan delegasi perempuan dari Vietnam Selatan juga melakukan hal yang sama. Saat itu, Nguyen Thi Binh merupakan jurnalis yang bekerja di surat kabar Liberation Daily News. 
Melalui surat kabar tersebut, Nguyen Thi Binh rutin menggelorakan semangat rakyat Vietnam Selatan untuk menggugat kekuatan pemerintahan yang menindas. Sebagaimana perlu diketahui, kondisi politik di Vietnam pada saat itu sangat tidak kondusif - meskipun pada tahun-tahun selanjutnya, kondisi Vietnam Selatan juga tidak jauh berubah akibat pemerintahan militer yang jatuh bangun (Ricklefs, peny. 2013: 578). Kembali pada sosok Nguye Thi Binh, selama menjadi seorang jurnalis, ia bersama suaminya yakni Ir. Tehniek juga bergabung dengan para pejuang di Vietnam Selatan untuk menentang kekuatan imperialis. Seringkali, perjuangan tersebut harus dilakukan di bawah tanah. Sayangnya, tidak banyak catatan yang ditinggalkan mengenai keterlibatan Nguyen Thi Binh dalam KWAA. Namun, Said (1963) memastikan bahwa gerak-gerik Nguyen Thi Binh selama konferensi berlangsung, menunjukkan bahwa Nguyen adalah perempuan pejuang, yang menentang keras kolonialisme dan imperialisme. Jika diperhatikan, baik Lucette Andrade maupun Nguyen merupakan dua tokoh yang sangat progresif. Memang, perlu disadari bahwa mayoritas jurnalis yang datang ke KWAA adalah mereka yang beraliran progresif (Dahlan, 2020: 288).

Berbeda dengan Nguyen Thi Binh yang harus berjuang secara radikal, Fan Chin, seorang delegasi dari RRT justru dapat sedikit lebih bebas dalam perjuangannya. Fan Chin merupakan jurnalis dari Peking Daily News, yang juga menjabatsebagaianggota parlemen Tiongkok. Selain itu, Fan Chin juga menduduki posisi sebagai Deputy President of All Journalists Association di Tiongkok (Said, 1963: 4). Selama konferensi berlangsung, Fan Chin menyampaikan kepada delegasi KWAA bahwa melalui penanya, seorang jurnalis dapat berperan banyak untuk negaranya. Salah satu perannya yang terpenting dalam konteks politik saat itu ialah membebaskan negara dari kekuasaan yang mengekang, seperti kekuasaan negara-negara kolonial. Meskipun pada kenyataannya, sulit bagi delegasi KWAA saat itu untuk mempercayai ucapan delegasi dari RRT, termasuk Fan Chin. Hal ini dikarenakan ada stigma bahwa RRT tidak jauh berbeda dengan Rusia di Blok Timur. Namun, dalam konferensi tersebut, Roeslan Abdulgani menegaskan bahwa “...djanganlah hendaknya kita 
mengira bahwa ... RRT adalah Rusia-nya Asia" (Abdulgani, 1963: 41). Menurut Roeslan Abdulgani (1963), dibanding membahas hal tersebut, maka lebih penting bagi para jurnalis Asia Afrika untuk mewaspadai kekuatan kolonialisme dan imperialisme yang bercokol di dua kawasan tersebut.

Meskipun para jurnalis perempuan di atas tidak semuanya mendapatkan kesempatan untuk berpidato secara resmi dalam konferensi, namun cerita-cerita mengenai perjuangan para perempuan tersebut yang tersebar selama konferensi memiliki nilai yang sangat penting bagi proses dekolonisasi di Asia dan Afrika secara umum. Bagaimanapun, cerita-cerita mereka dalam mendobrak kekuatan penjajah, menunjukkan kepada seluruh delegasi KWAA bahwa kolonialisme dan imperialisme masih berlangsung di Asia dan Afrika. Karenanya, para jurnalis perempuan tersebut mengajak seluruh jurnalis Asia Afrika untuk memberikan dukungan pada upaya dekolonisasi. Para jurnalis perempuan tersebut juga mendukung setiap agenda konferensi yang mengutuk kolonialisme dan imperialisme.

Kutukan tersebut antara lain ditujukan kepada kekuatan Blok Barat dan Blok Timur yang dapat menjadikan negara-negara Asia dan Afrika sebagai negara jajahan, hingga kekuatan internal di dalam kawasan Asia Afrika sendiri yang berpotensi menumbuhkan penindasan dan penjajahan dalam bentuk apapun. Termasuk dalam ancaman internal ini adalah imperialisme Israel yang dinilai dapat menghancurkan laju dekolonisasi di kawasan Arab ("Tool of Powers", 10 Mei 1963: 11). Dukungan para jurnalis perempuan terhadap semangat dekolonisasi ini tentu secara tidak langsung mempengaruhi para peserta konferensi untuk turut menggelorakan semangat antikolonialisme dan antiimperialisme. Meskipun pada kenyataannya, perlu disadari bahwa sebagian pihak menilai bahwa melibatkan jurnalis dan pers dalam perjuangan melawan kekuatan kolonial adalah menjauhkan para jurnalis dari prinsip netralitasnya.

Pada dasarnya, menjadi wajar jika jurnalis yang menjadi delegasi dalam KWAA menjadi bagian dari gerakan dekolonisasi. Selain memang berakar dari Dasasila Bandung yang mengutuk keras kolonialisme dalam segala bentuk, 
KWAA juga menjadi bagian dari ruang diplomasi pascakolonial di Asia Afrika yang memang agenda utamanya ialah menghancurkan kolonialisme. Hal ini dibenarkan oleh Hartini Soekarno yang pada penutupan KWAA menegaskan bahwa rakyat Asia Afrika termasuk di dalamnya para jurnalis berada di garis terdepan untuk mengenyahkan kolonialisme dan imperialisme (Lestari, Juni 2014: 192). Hartini Soekarno dalam hal ini sebenarnya memiliki peranan yang sangat penting untuk meyakinkan bahwa perempuan (termasuk para jurnalis) memiliki kekuatan dan kemampuan untuk mengganyang kolonialisme dan terlibat dalam gerak dekolonisasi. $^{2}$

Kembali pada persoalan peran jurnalis dalam dekolonisasi, jurnalis yang dianggap sebagai profesi yang bersifat netral - dalam arti tidak mencampuri urusan politik - menurut Soebandrio, justru sangat berkaitan dengan politik luar negeri dan diplomasi ("Politik L. N. Indonesia...", 1963: 7). Bagi negara-negara kolonialis (colonizer), pers merupakan alat perjuangan, terutama untuk menindas dan merendahkan orang-orang yang dijajah. Atau dengan kata lain, pers menjadi alat dalam menciptakan psychological warfare, dimana berita yang dimuat dapat menciptakan keresahan dan perasaan inferior bagi masyarakat jajahan. Karenanya, prinsip kebebasan pers (freedom of press) tidak lagi diterapkan. Begitu pula bagi wilayah jajahan ataupun negara-negara yang baru merdeka, pers turut menjadi alat perjuangan.

Terutama dalam dinamika sosial politik tahun 1950an hingga tahun 1960an, pers menjadi media untuk menyebarkan semangat antikolonialisme. Presiden Soekarno dalam pidatonya pada tahun 1965 bahkan secara khusus menyebutkan bahwa pers merupakan media modern untuk revolusi kemerdekaan (Soekarno, Agustus 1965). Karenanya, jurnalis yang menjadi agen ataupun aktor dalam pers tersebut juga menjadi bagian dari gerakan antikolonialisme di Asia

\footnotetext{
${ }^{2}$ Hartini Soekarno sebenarnya sangat aktif dalam menyuarakan revolusi, antikolonialisme, dan segala sesuatu yang berhubungan dengan dekolonisasi. Dalam KWAA, Hartini berperan penting untuk melakukan penggalangan dana. Lebih lanjut lihat di: Rosihan Anwar, Sukarno, Tentara, PKI: Segitiga Kekuasaan sebelum Prahara Politik 1961-1965, (Jakarta: Yayasan Obor Indonesia, 2006), hlm. 282-283.
} 
Afrika hingga level global. Bahkan, dengan adanya peran jurnalis perempuan, secara tidak langsung telah muncul perasaan yang disebut sebagai "global sisterhood" dalam pers di Asia dan Afrika (Bier dalam Lee, peny., 2010: 152). Meskipun Bier menyebutkan istilah tersebut untuk menjelaskan perempuan dan pers dalam konteks Mesir, namun istilah ini cukup relevan untuk digunakan dalam konteks Asia dan Afrika secara keseluruhan. Jika diperhatikan secara mendetail, maka pers terutama yang dikendalikan oleh para jurnalis perempuan memberikan ruang yang cukup luas untuk mengulas upaya dekolonisasi di dalam dan di luar negeri beserta para tokoh perempuan yang terlibat.

Keterlibatan delegasi perempuan secara umum juga memberikan dampak yang lebih luas, dimana gerakan dekolonisasi di Asia dan Afrika tidak hanya menjadi ruang milik laki-laki, tetapi juga milik kaum perempuan - terlepas dari posisi mereka apakah merupakan seorang ibu rumah tangga ataupun perempuan pekerja. Selain itu, peranan para delegasi perempuan tersebut juga turut menjadikan KWAA sebagai salah satu konferensi yang sangat penting sepanjang masa pemerintahan Soekarno. Bahkan, KWAA juga dianggap sebagai salah satu bukti kemenangan Indonesia dalam politik luar negeri (Chisaan, dalam Lindsay dan Liem, 2012: 287).

\section{PENUTUP}

Konferensi Wartawan Asia Afrika (KWAA) tahun 1963 menjadi salah satu warisan Bandung 1955 yang sangat penting. Pelaksanaan konferensi ini telah menunjukkan bahwa semangat Bandung 1955 tidak hanya menyentuh aktor-aktor negara, tetapi juga menyentuh kalangan non-state atau orang-orang di luar birokrasi negara. Jurnalis yang sebelumnya dianggap sebagai orang-orang yang netral, dalam arti tidak mengurus masalah politik, bertransfromasi menjadi salah satu agen penentang kolonialisme dan imperialisme. Hal ini sangat terlihat dalam pelaksanaan KWAA. Meskipun melalui perdebatan yang panjang, KWAA pada akhirnya mengakar pada Dasasila Bandung. Pada dasarnya, semangat antikolonialisme, antiimperialisme, dan kesepakatan untuk mengingat kembali 
Dasasila Bandung juga tidak dapat dilepaskan dari pengaruh Soekarno. Bagaimanapun, harus disadari bahwa sejak pelaksanaan KAA 1955, Soekarno bukan lagi hanya tampil sebagai Presiden Indonesia, melainkan juga sebagai “pemimpin” Dunia Ketiga.

Dalam memperkuat antikolonialisme dan antiimperialisme di KWAA, delegasi perempuan menjadi bagian yang tidak dapat diabaikan begitu saja. Meskipun tidak banyak delegasi perempuan yang menduduki presidium ataupun posisi penting selama KWAA, namun mereka turut berperan dalam memperkuat solidaritas antikolonialisme dan antiimperialisme. Delegasi perempuan baik dari Indonesia, Sierre Leone, dan beberapa negara lainnya turut menyumbang proses dalam KWAA untuk mengingatkan para delegasi pada komitmen Dasasila Bandung. Namun, cara yang dilakukan para delegasi perempuan untuk memperkuat semangat antikolonialisme dan antiimperialisme tidak melalui pidato sambutan dan semacamnya. Mereka menyadarkan para delegasi melalui cerita pengalaman mereka sebagai "buronan" penjajah di negaranya masing-masing. Bagaimanapun, cerita-cerita tersebut menyadarkan para delegasi KWAA bahwa kolonialisme dan imperialisme masih ada di Asia dan Afrika hingga saat itu. 


\section{DAFTAR PUSTAKA}

Abdulgani, Roeslan. 1963. "Bandung Spirit dan Pers Asia Afrika". Majalah Wanita. Vol. 16. No. 3-4. Hlm. 10-11, Hlm. 41, Hlm. 63.

Aggestam, Karin, dan Ann Towns. 2018. "The Gender Turn in Diplomacy: A New Research Agenda". International Feminist Journal of Politics. Vol. 21. No. 1. Hlm. 9-28.

Agung, Ida Anak Agung Gde. 1990. Twenty Years Indonesian Foreign Policy 1945-1965. Yogyakarta: Duta Wacana University Press.

Anonim. 10 Mei 1963. "Tool of Powers". The Australian Jewish News. Hlm. 11.

Anonim. 1963. "Politik L. N. Indonesia dan Diplomasi di Bidang Djurnalistik". Mimbar Penerangan. Vol. 14. No. 4. Hlm. 7-11.

Anonim. Desember 1963. "Mengenang Kembali Peristiwa Penting Tahun 1963". Mimbar Penerangan. Vol. 14. No. 5. Hlm. 75-81.

Anonim. Februari 1963. "Sukses dalam K.W.A.A". Majalah Wanita. Vol. 16. No. 2. Hlm. 1.

Anonim. Juni 1963. “K.W.A.A. Penting bagi Perdjuangan Menentang Imperialisme dan Kolonialisme II". Mimbar Penerangan. Vol. 14. No. 2. Hlm. 53-61.

Anonim. Maret 1963. "Wanita Menjambut K.W.A.A.”. Majalah Wanita. Vol. 16. No. 6. Hlm. 1.

Anonim. Mei 1963. “K.W.A.A. Penting bagi Perdjuangan Menentang Imperialisme dan Kolonialisme I". Mimbar Penerangan. Vol. 14. No. 1. Hlm. 42-46.

Anwar, Rosihan. 2006. Sukarno, Tentara, PKI: Segitiga Kekuasaan sebelum Prahara Politik 1961-1965. Jakarta: Yayasan Obor Indonesia.

Armstrong, Elisabeth. 2016. "Before Bandung: The Anti-Imperialist Women's Movement in Asia and the Women 's International Democratic Federation". Signs: Journal of Women in Culture and Society. Vol. 41. No. 2. Hlm. 305-331.

Bier, Laura. 2010. "Feminism, Solidarity, and Identity in the Age of Bandung: Third World Women in the Egyptian Women's Press", dalam Christopher 
J. Lee. Making A World After Empire: The Bandung Moment and Its Political Afterlives. Athens: Ohio University Press.

Chisaan, Choirotun. 2012. "In Search of An Indonesian Islamic Cultural Identity, 1956-1965", dalam Jennifer Lindsay dan Maya H. T. Liem (peny.). Heirs to World Culture: Being Indonesian 1950-1965. Leiden: KITLV Press.

Dahlan, Muhidin M. 2020. Politik Tanpa Dokumen. Yogyakarta: Penerbit Bokoe.

Jansen, Jan C. 2017. Decolonization: A Short History. Princeton: Princeton University Press.

Jati, Wasisto Raharjo. 2014. "Historisitas Politik Perempuan Indonesia". Paramita. Vol. 24. No. 2. Hlm. 200-210.

Kuntowijoyo. 2013. Pengantar Ilmu Sejarah. Yogyakarta: Penerbit Tiara Wacana.

Leifer, Michael. 1989. Politik Luar Negeri Indonesia. Jakarta: Gramedia.

Lestari, Siska Nurazizah. Juni 2014. "Konferensi Wartawan Asia Afrika di Jakarta Tahun 1963: Suatu Manifestasi NEFOS (New Emerging Forces)". Patrawidya. Vol. 15. No. 2. Hlm. 183-198.

McGregor, Katharine E. 2013. "The Cold War, Indonesian Women, and the Global Antiimperialist Movement, 1946-1965", dalam Jadwiga E. Pieper Mooney dan Fabio Lanza (peny.). De-centering Cold War History: Local and Global Change. London dan New York: Routledge.

Minarova-Banjac, Cindy. 2018. "Gender Culture in Diplomacy: A Feminist Perspective". Dalam Culture Mandala. Vol. 13. No. 1. Hlm. 20-44.

Panitia Penulisan Sejarah Diplomasi Republik Indonesia. 1996. Sejarah Diplomasi Republik Indonesia dari Masa ke Masa. 4 Jilid. Jakarta: Departemen Luar Negeri RI.

Ricklefs, M. C. (peny.). 2013. Sejarah Asia Tenggara dari Masa Prasejarah sampai Kontemporer. Depok: Komunitas Bambu.

Ricklefs, M. C. 2008. Sejarah Indonesia Modern 1200-2008. Jakarta: Penerbit Serambi.

Said, Lies. 1963. "Siapakah Mereka Ini dan Bagaimana Perdjuangannya?". Majalah Wanita. Vol. 16. No. 8. Hlm. 2-5. 
Soekarno. Agustus 1965. "Tjapailah Bintang-Bintang di Langit: Tahun Berdikari”. Mimbar Indonesia. Vol. 19. No. 8. Hlm. 4-13, Hlm. 18-20.

Stone, Katherine H. Desember 1955. "Peranan Wanita di Medja PBB". Dunia Wanita. Vol. 7. No. 24.

Tickner, J. Anne. 1992. Gender in International Relations: Feminist Perspectives on Achieving Global Security. New York: Colombia University Press.

Utama, Wildan Sena. 2017. Konferensi Asia Afrika 1955: Asal Usul Intelektual dan Warisannya bagi Gerakan Global Antiimperialisme. Tangerang: Marjin Kiri.

Vreede-de Stuers, Cora. 2008. Sejarah Perempuan Indonesia, Gerakan dan Pencapaian. Jakarta: Komunitas Bambu.

Wulandari, Ayu. 2020. "Kaum Perempuan dalam Diplomasi Kebudayaan Indonesia, 1945-1960an”. Jurnal Penelitian Sejarah dan Budaya. Vol. 6. No. 2. Hlm. 319-342.

Wuryandari, Ganewati (peny.). 2008. Politik Luar Negeri Indonesia di Tengah Pusaran Politik Domestik. Yogyakarta: Pustaka Pelajar bekerjasama dengan Pusat Penelitian Politik LIPI.

Zhou, Taomo. 2019. "Global Reporting from the Third World: The Afro-Asian Journalists' Association, 1963-1974". Critical Asian Studies. Vol. 51. No. 2. Hlm. 166-167. 